NATIONAL LABORATORY

MANAGED BY UT-BATTELLE

FOR THE DEPARTMENT OF ENERGY

\title{
Economic Evaluation for the Production of Sorbents and Catalysts Derived from Hydrous Titanium Oxide Microspheres Prepared by the HMTA Internal Gelation Process
}

April 2000 

Chemical Technology Division

\title{
Economic Evaluation for the Production of Sorbents and Catalysts Derived from Hydrous Titanium Oxide Microspheres Prepared by the HMTA Internal Gelation Process
}

\author{
J. L. Collins \\ J. S. Watson
}

Date Published-April 2000

Prepared for the U.S. Department of Energy, Office of Science and Technology Efficient Separations and Processing Crosscutting Program

Prepared by the OAK RIDGE NATIONAL LABORATORY

P.O. Box 2008

Oak Ridge, Tennessee 37831-6285.

managed by

UT-BATTELLE, LLC

for the

U.S. DEPARTMENT OF ENERGY

under contract DE-AC05-00OR22725 



\section{CONTENTS}

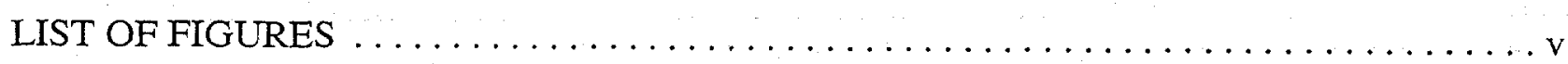

LIST OF TABLES $\ldots \ldots \ldots \ldots \ldots \ldots \ldots \ldots \ldots \ldots \ldots \ldots \ldots \ldots \ldots \ldots \ldots$

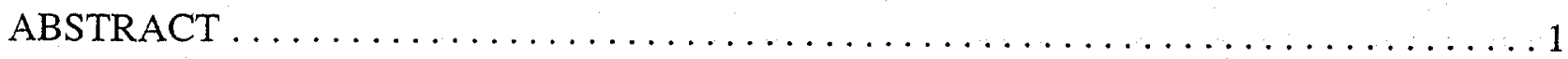

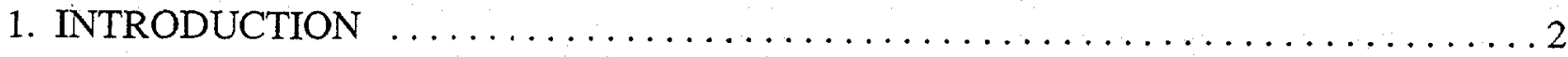

1.1 Sphere-Forming Technology: Need and History $\ldots \ldots \ldots \ldots \ldots \ldots \ldots \ldots \ldots$

1.2 HMTA/Urea Internal Gelation Process Technology $\ldots \ldots \ldots \ldots \ldots \ldots \ldots \ldots$

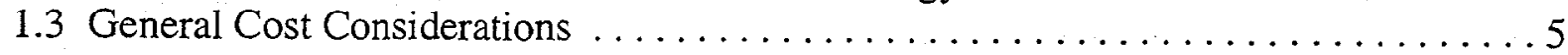

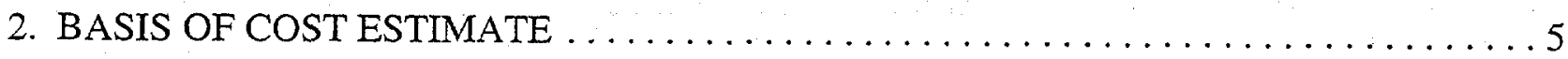

3. ANNUAL COST ESTIMATE FOR LABORATORY-SCALE FACILITY. $\ldots \ldots \ldots \ldots 13$

4. ANNUAL COST ESTIMATE FOR PILOT-SCALE FACILITY. ............. 16

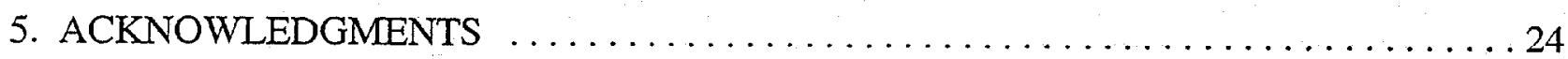

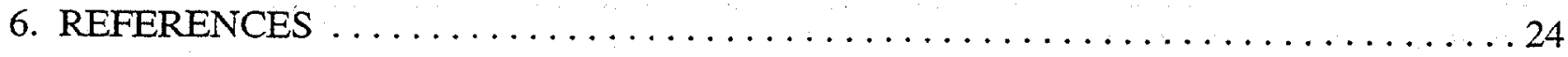




\section{LIST OF FIGURES}

Figure

1 Laboratory-scale system for forming microspheres with a single-needle,

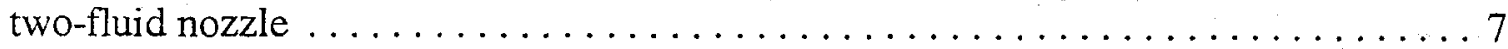

2 Schematic of the laboratory-scale system for preparing microspheres with a single-needle, two-fluid nozzle $\ldots \ldots \ldots \ldots \ldots \ldots \ldots \ldots \ldots \ldots \ldots$

3 Laboratory-scale system for forming monodispersed microspheres with

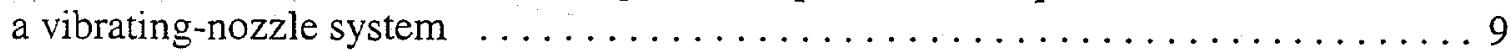

4 Schematic of single-fluid pulsed tubular nozzles used to increase the

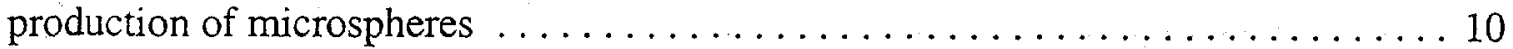

$5 \quad$ Internal gelation process for preparation of dried gel spheres $\ldots \ldots \ldots \ldots \ldots \ldots 17$

6 Continuous internal gelation concepts using silicone oil and

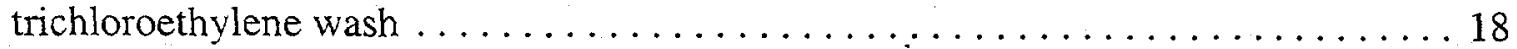

7 Schematic of continuous perchloroethylene-based gel sphere engineering

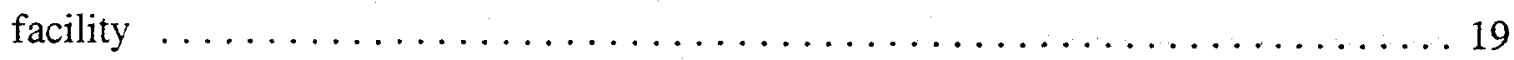

8 Initial design of float-gelation trough for using perchloroethylene as

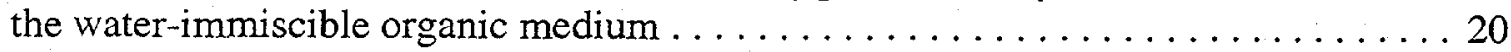


- 


\section{LIST OF TABLES}

Table

Page

1 Chemical costs for HTiO preparation $\ldots \ldots \ldots \ldots \ldots \ldots \ldots \ldots \ldots \ldots \ldots$

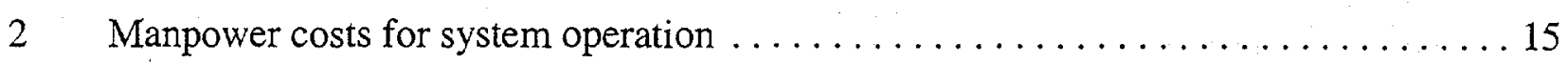

3 Summary of annual product costs for laboratory-scale facility $\ldots \ldots \ldots \ldots \ldots$

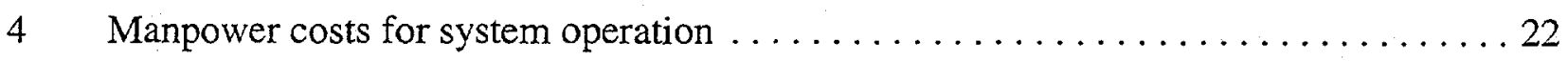

5 Summary of annual product costs for a pilot-scale facility at $2.4-\mathrm{lb} / \mathrm{h}$ production . . . 23 . 


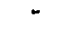




\begin{abstract}
Hydrous metal oxides of $\mathrm{Zr}, \mathrm{Ti}, \mathrm{Hf}, \mathrm{Fe}, \mathrm{Al}$, etc. are inorganic ion exchangers that have high selectivities and efficiencies for separating and removing fission products, actinides, and other undesirable elements from aqueous waste streams. In most cases, these ion exchangers are commercially available only as fine powders or as unstable granular particles that are not readily adaptable to continuous processing techniques such as column chromatography.

Hydrous metal oxides can be prepared as microspheres by the internal gelation process. This process is unique in that it provides a means of making a usable engineered form of inorganic ion exchanger that can be used in large-scale column separations. With such material, the flow dynamics in column operations would be greatly enhanced. In addition, the microspheres are in a stable form that has little or no tendency to degrade under dynamic conditions. Another advantage of the process is that the gelation time and size of the microspheres can be controlled. Also, microspheres can be reproducibly prepared on either a small or a large scale-which is not always true for batch preparation of the powdered or granular forms.

The use of these materials can be expanded in a number of ways. The process allows for the microspheres to be homogeneously embedded with fine particles of other selective ion exchangers, and for the microspheres (undried) to be chemically converted to microspheres of other ionexchanger materials such as phosphates, silicophosphates, hexacyanoferrates, tungstates, and molybdates.

This report presents an economic evaluation of the preparation of hydrous titanium oxide (HTiO) microspheres by an internal gelation process for use in making ion exchangers, catalysts, and getters. It also examines the estimated costs for a company to produce the material but does not discuss the price to be charged since that value would take into account company policy-matters that cannot be covered here. Since the volume of business is not known, the costs were bracketed between the laboratory-scale system of making 1 to $2 \mathrm{lb}$ HTiO/d of dried beads per 8-h day and a small pilot-scale system of producing 1 to $2.4 \mathrm{lb} \mathrm{HTiO} / \mathrm{h}$. The best esimates were between $\$ 286$ and $\$ 534$ for the laboratory-scale production of 520 and $260 \mathrm{lb} /$ year, respectively, and between $\$ 93$ and $\$ 107$ for the pilot-scale production of 1.5 tons/year. The costs of producing microspheres in a pilot-
\end{abstract}


scale facility will be strongly dependent on the scale of the facility and the fraction of time it is used. The preparation of inorganic materials as microspheres has the potential for many additional applications. If these applications prove to be feasible, the cost of producing the materials could be decreased even further.

\section{INTRODUCTION}

\subsection{SPHERE-FORMING TECHNOLOGY: NEED AND HISTORY}

Hydrous metal oxides of $\mathrm{Ti}, \mathrm{Zr}, \mathrm{Hf}, \mathrm{Fe}, \mathrm{Al}$, etc.; monohydrogen phosphates of $\mathrm{Ti}$ and $\mathrm{Zr}$; titanates; silicotitanates; tungstates; molybdates; molybdophosphates; phosphotungstates; polyantimonic acid; and hexacyanoferrates are inorganic ion exchangers that have high selectivities and efficiencies for separating and removing fission products (e.g., cesium, europium, cerium, ruthenium, zirconium, and strontium), actinides, and other elements (e.g., as silver, lead, mercury, nickel, zinc, chromium, and fluoride) from aqueous waste streams. ${ }^{1-3}$ However, in most cases, sorbents prepared from these materials are commercially available only as fine powders or as unstable granular particles that are not readily adaptable to continuous processing techniques such as column chromatography. Some of these powders are also prepared in the form of pellets by using binding materials; however, the binders tend to decrease the number of exchange sites that are available for use. The binders tend to block pores and passageways to the exchange sites within the structures and adversely affect the loading and kinetic behavior of the exchangers.

The hexametylenetetramine (HMTA)/urea internal gelation technology that has been developed over the last decade provides a means of preparing many inorganic ion-exchange materials in an engineered form as microspheres, which can improve the flow dynamics for column operations and expand the practical applications of these materials. ${ }^{4-6}$ The present effort is a development extension of the work in the 1970s and early 1980s for making nuclear reactor fuels. ${ }^{7-14}$ During the past 3 years, the microsphere development work has been funded by the DOE Office of Science and Technology's Efficient Separations and Processing Crosscutting Program. Some of the highlights of the program were as follows: 
The development and evaluation tasks for making NaTi microspheres by three different methods were completed.

- A U.S. patent (No. 5,821,186) entitled "Method of Preparing Hydrous Titanium Oxide Spherules and Other Gel-Forms Thereof" was issued on October 13, 1998.

- A patent disclosure, "Method of Preparing Hydrous Zirconium Oxide Spherules and Other Gel-Forms Thereof" was submitted to the ORNL Office of General Patent Counsel in September 1998.

- Eichrom Industries, Inc. (Darien, Illinois) obtained a license for the HTiO patent technology in June 1997. (Eichrom is also interested in obtaining the license for the HZrO patent disclosure.)

- In a Work for Others contract with Eichrom Industries, Inc., HTiO-(NUCLEOSIL resin) microspheres were developed. In subsequent tests, they proved to be very effective in removing technetium from solutions of low ionic strength. ${ }^{13}$

- The development and evaluation tasks for preparing AMP-ZrHP microspheres was completed. Samples of these microspheres were shipped to the Idaho National Engineering and Environmental Laboratory for testing.

\subsection{HMTA/UREA INTERNAL GELATION PROCESS TECHNOLOGY}

The chemistry of the HMTA internal gelation process has been described in detail in a report by J. L. Collins et al. ${ }^{7}$ The results of previous studies showed that four principal reactions were involved in the hydrolysis and precipitation of uranyl nitrate hexahydrate and that the kinetics and equilibria of these reactions varied with temperature. The chemical behavior observed during those studies should hold true for making microspheres of other hydrous metal oxides by the HMTA internal gelation process. The four reactions involved in preparing hydrous titanium oxide from chilled broths containing acidified titanium tetrachloride, HMTA, and urea can be shown as follows:

complexation/decomplexation,

$$
2 \mathrm{CO}\left(\mathrm{NH}_{2}\right)_{2}+\mathrm{Ti}^{4+}=\mathrm{Ti}\left[\mathrm{CO}\left(\mathrm{NH}_{2}\right)_{2}\right]_{2}^{4+}
$$


hydrolysis,

$$
\begin{aligned}
& \mathrm{Ti}^{4+}+\mathrm{xH}_{2} \mathrm{O}=\mathrm{Ti}(\mathrm{OH})_{4} \cdot \mathrm{yH}_{2} \mathrm{O}+4 \mathrm{H}^{+} \text {and } \\
& \mathrm{TiO}^{2+}+\mathrm{xH}_{2} \mathrm{O}=\mathrm{TiO}(\mathrm{OH})_{2} \bullet \mathrm{yH}_{2} \mathrm{O}+2 \mathrm{H}^{+}
\end{aligned}
$$

HMTA protonation,

$$
\left(\mathrm{CH}_{2}\right)_{6} \mathrm{~N}_{4}+\mathrm{H}^{+}=\left(\mathrm{CH}_{2}\right)_{6} \mathrm{~N}_{4} \mathrm{CH}^{+} \text {; and }
$$

\section{HMTA decomposition,}

$$
\left(\mathrm{CH}_{2}\right)_{6} \mathrm{~N}_{4} \mathrm{CH}^{+}+3 \mathrm{H}^{+}+6 \mathrm{H}_{2} \mathrm{O}=4 \mathrm{NH}_{4}^{+}+6 \mathrm{CH}_{2} \mathrm{O} \text {. }
$$

The major constituents for most broths used for making microspheres of hydrous metal oxide are HMTA, urea, and a metal salt. Urea serves as a complexing agent for the metal (reaction 1) and at certain concentrations allows for stable broths to be prepared at $\sim 0^{\circ} \mathrm{C}$ that remain clear and free of gelation or precipitation for reasonable periods of time. As the temperature of the broth droplets rises in the hot organic medium, decomplexation occurs (reaction 1) and thus allows hydrolysis of the titanium (reaction 2). HMTA, a weak organic base, drives the hydrolysis reaction to completion. At first, the HMTA molecules are singularly protonated (reaction 3). After most of the HMTA molecules ( $95 \%$ ) are protonated, however, they begin to decompose (reaction 4 ) into ammonium ions, which make the system even more basic. Each protonated HMTA molecule can effectively remove three additional hydrogen ions. The reaction products are ammonium chloride and formaldehyde. In addition to being a complexing agent, urea also functions as a catalytic agent in the decomposition of protonated HMTA molecules.

One of the more interesting features of the chemistry of the process is the conversion of the reaction products back to HMTA in the basic wash step. When the microspheres are washed with dilute solutions of $\mathrm{NH}_{4} \mathrm{OH}$ to remove the reaction products $\left(\mathrm{NH}_{4}{ }^{+}\right.$and $\left.\mathrm{CH}_{2} \mathrm{O}\right)$, the reaction products react to re-form HMTA,${ }^{15}$ which is washed from the microspheres along with any unreacted urea. This feature makes it possible, by chemical adjustments with $\mathrm{NH}_{4} \mathrm{Cl}$ and $\mathrm{CH}_{2} \mathrm{O}$, to convert the wash solutions back to HMTA/urea solutions that can be reused. The reaction of $\mathrm{NH}_{4} \mathrm{Cl}$ and $\mathrm{CH}_{2} \mathrm{O}$ to form HMTA is most efficient in the $\mathrm{pH}$ range of 6 to 8 . This feature aids in making the HMTA internal gelation process even more economically attractive. 


\subsection{GENERAL COST CONSIDERATIONS}

The cost of producing a pound of the materials described above can vary strongly with the scale of the operation. When new products such as these are brought to market, the manufacturer usually produces the first quantities in relatively small equipment since the initial demand will be small-probably limited to small quantities for tests and demonstrations. As the merits of the materials become more evident and their success in demonstrations is confirmed, the demand will increase and larger-scale operations will be needed. Thus, the cost of producing the material can decrease with time and with increases in demand. The price that a company decides to charge for the material would depend on other factors as well as the cost of production. The company could demand a significant profit or a rapid write-off of any of its own development and testing costs. On the other hand, some companies might decide to restrain the cost during the initial stages of production, when costs per pound are high, in an effort to stimulate the market for the materials.

This report only examines the estimated costs for the company to produce the material-not the price they would charge the customer since the latter value would take into account company policy (matters that cannot be covered in this report). Recognizing that the costs to produce these materials will vary strongly with production rate, this report discusses at the expected initial costs for relatively small production rates and then considers the likely costs for large-scale operation. Since these materials, as well as similar materials, have been produced by using small bench-scale equipment, the nature of the equipment required for such operations is well known. The costs and throughput of larger-scale equipment will depend on the skills of the design engineers employed by the manufacturer and on the existing equipment in the manufacturer's facilities. Although it is not likely that an accurate and reliable estimate can be developed for the larger facilities at this time, the available information allows us to bracket the expected costs that the manufacturer is likely to achieve into a reasonably narrow and meaningful range.

\section{BASIS OF COST ESTIMATE}

In preparing a detailed cost estimate, it is important to know the volume of business that may be involved. Sphere-producing facilities that were built in the late 1970 s and early 1980 s for the 
production of nuclear reactor fuels ranged from laboratory scale at ORNL, which had the potential of producing 1 to $2 \mathrm{lb}$ of uranium (U) per day $(8 \mathrm{~h})$, to a small pilot scale at ORNL, ${ }^{12}$ which demonstrated production of 1 to $2.4 \mathrm{lb} \mathrm{U} / \mathrm{h}$-and to an even larger-scale plant (also a pilot-scale plant) that was built by Exxon Nuclear Company, Inc. ${ }^{16-18}$ in Richland, Washington, based on ORNL technology that could produce several kilograms of uranium per hour. Exxon engineers were able to modify the system design for a larger plant line that would have produced $44 \mathrm{lb}$ of wet spheres per hour, or about $220 \mathrm{lb}$ U/day. Although the larger-scale Sphere-Pac plant was not actually constructed, many of the system components were built and tested. Since the volume of business is not known, the costs for this estimate are bracketed between the laboratory-scale system for making 1 to $2 \mathrm{lb} \mathrm{HTiO/day} \mathrm{(} 8 \mathrm{~h}$ ) of dried beads and a small pilot-scale system for producing 1 to $2.4 \mathrm{lb} \mathrm{HTiO} / \mathrm{h}$.

Two types of laboratory-scale systems are located in hoods in Building 4501 at ORNL. The first type, shown in Figs. 1 and 2, makes use of single-necdle, two-fluid-nozzle system that is capable of producing 1 to $2 \mathrm{lb} /$ day $(8 \mathrm{~h})$ of dried HTiO microspheres per day $(8 \mathrm{~h})$. The second system, which is used for making monodispersed microspheres with a vibrating-nozzle apparatus, is shown in Fig. 3. A tubular nozzle with two or three orifices would be needed for comparable production. Production could be increased with the use of a nozzle with five or seven orifices (Fig. 4).

Eichrom Industries, Inc., the company that has licensed this technology, will likely start its production of microspheres with laboratory-scale apparatus in order to better understand the technology and to establish a sufficient market to justify a larger-scale operation. If a hood is already available, the investment in equipment to start making microspheres would be less than $\$ 20 \mathrm{~K}$. The primary costs would come largely from labor to operate the apparatus and from the purchase of chemicals. Numerous undergraduate students have worked on the development of the internal gelation process at ORNL. These students had little difficulty in using the two-fluid nozzle apparatus to make microspheres after only a few days of training; however, a few additional days of training were required when the vibrating-nozzle apparatus was used. Either of these two laboratory-scale versions could be operated continuously to increase production.

The laboratory-scale apparatus used in this program (Figs. 1 and 2) to make the HTiO spherules consisted of a reservoir for heating the silicone oil, a pump for circulating the silicone oil, 


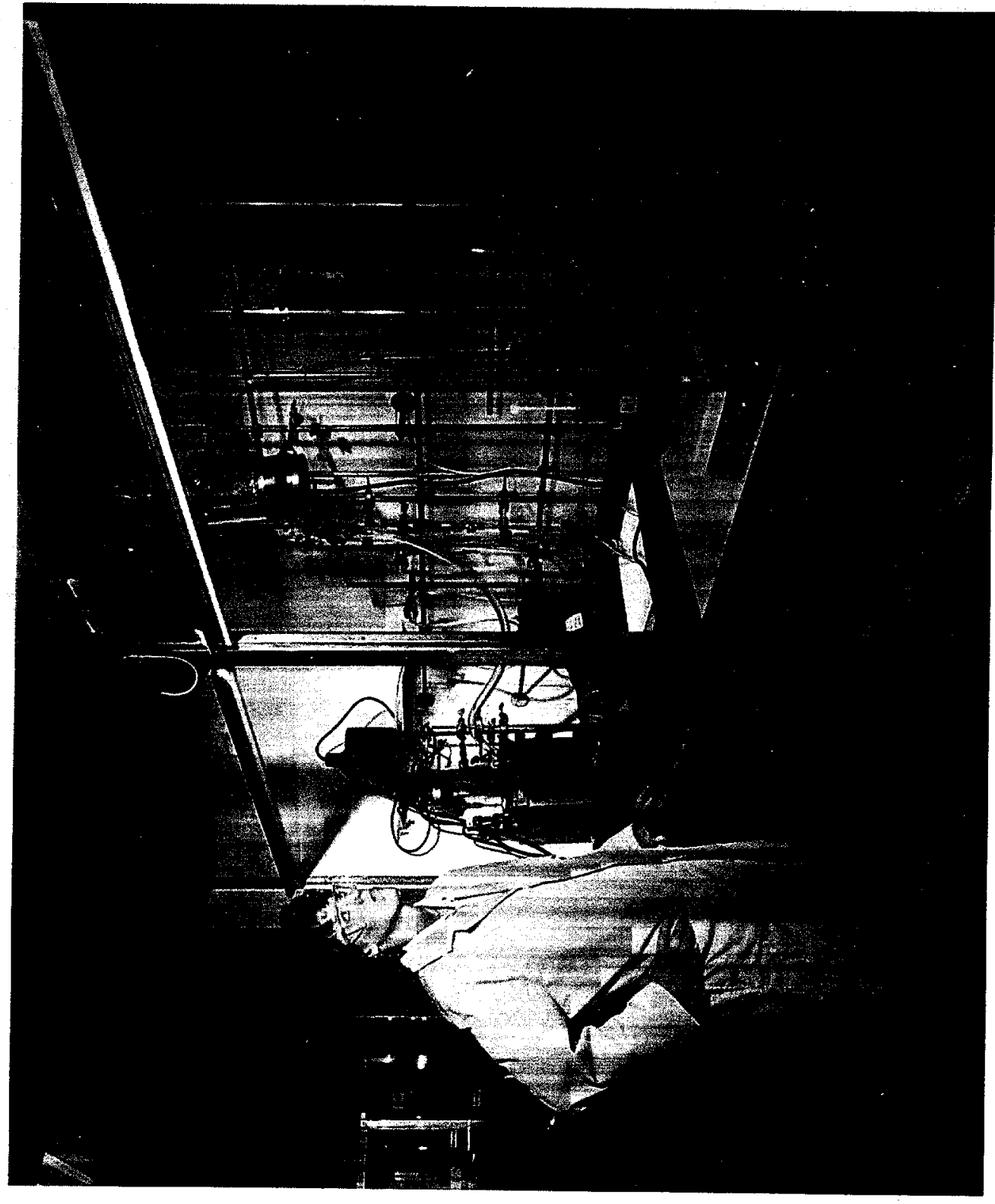

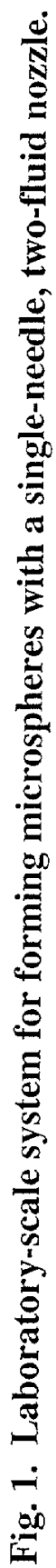




\section{AN INTERNAL GELATION GEL-SPHERE APPARATUS}

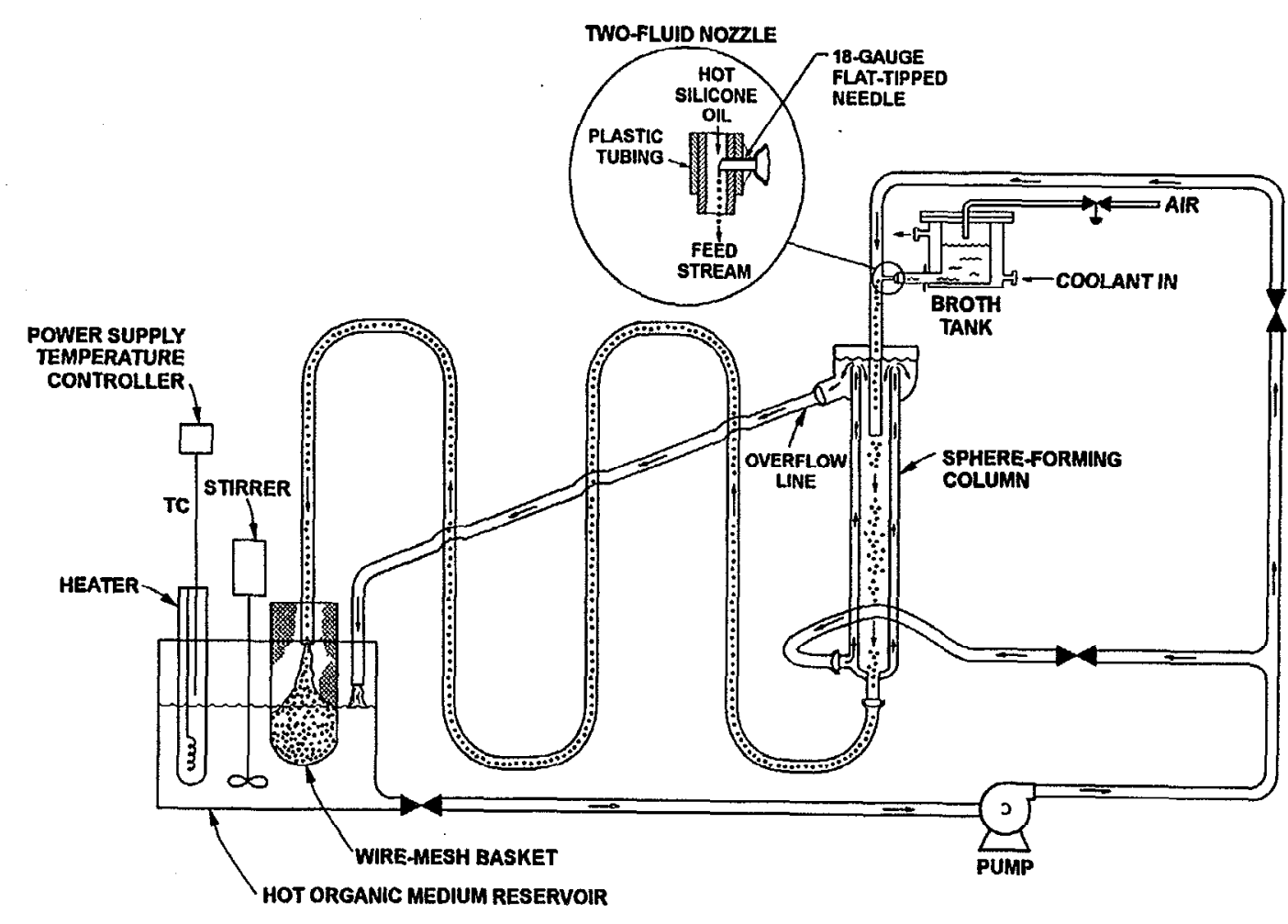

Fig. 2. Schematic of the laboratory-scale system for preparing microspheres with a single-needle, two-fluid nozzle. 


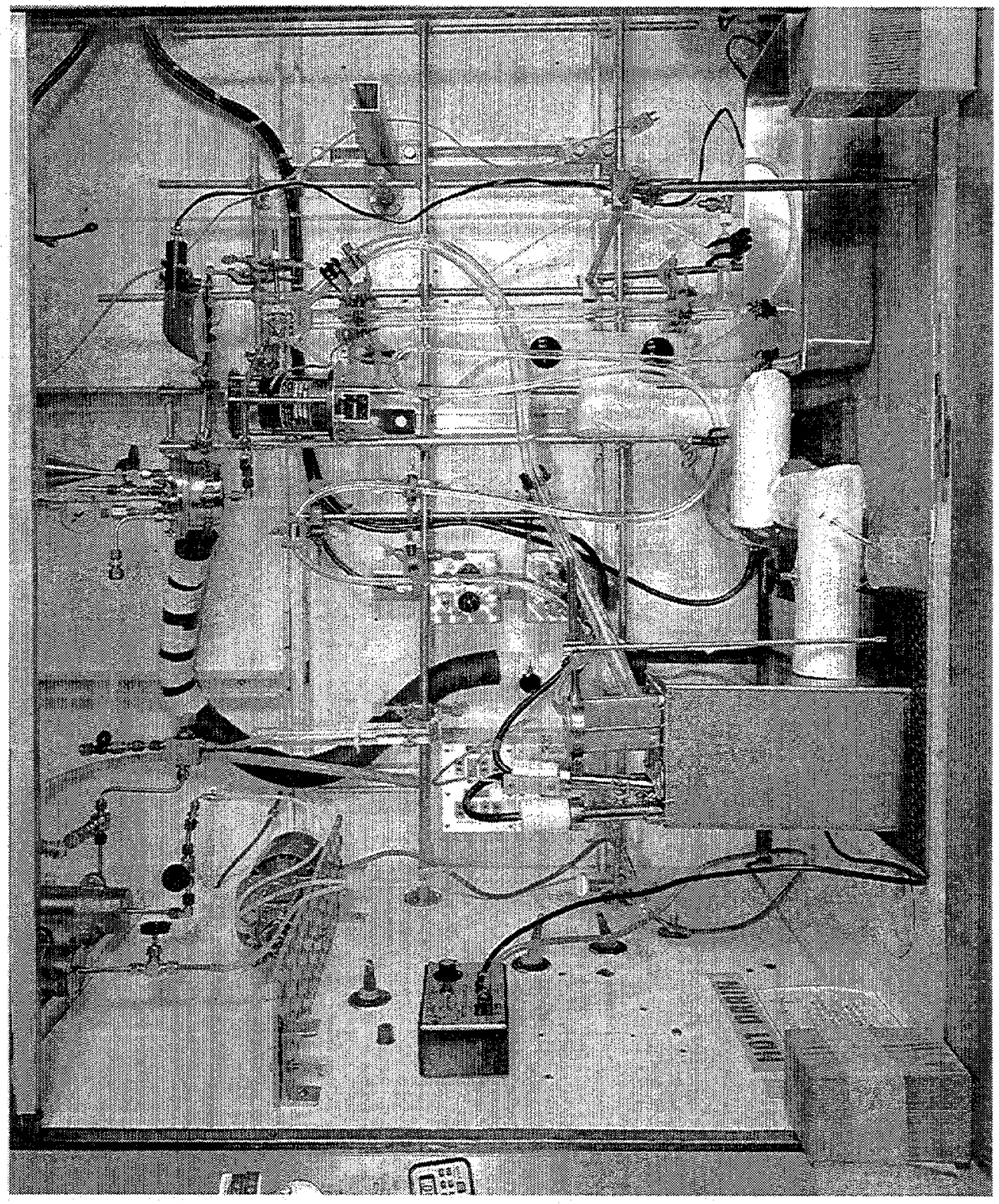




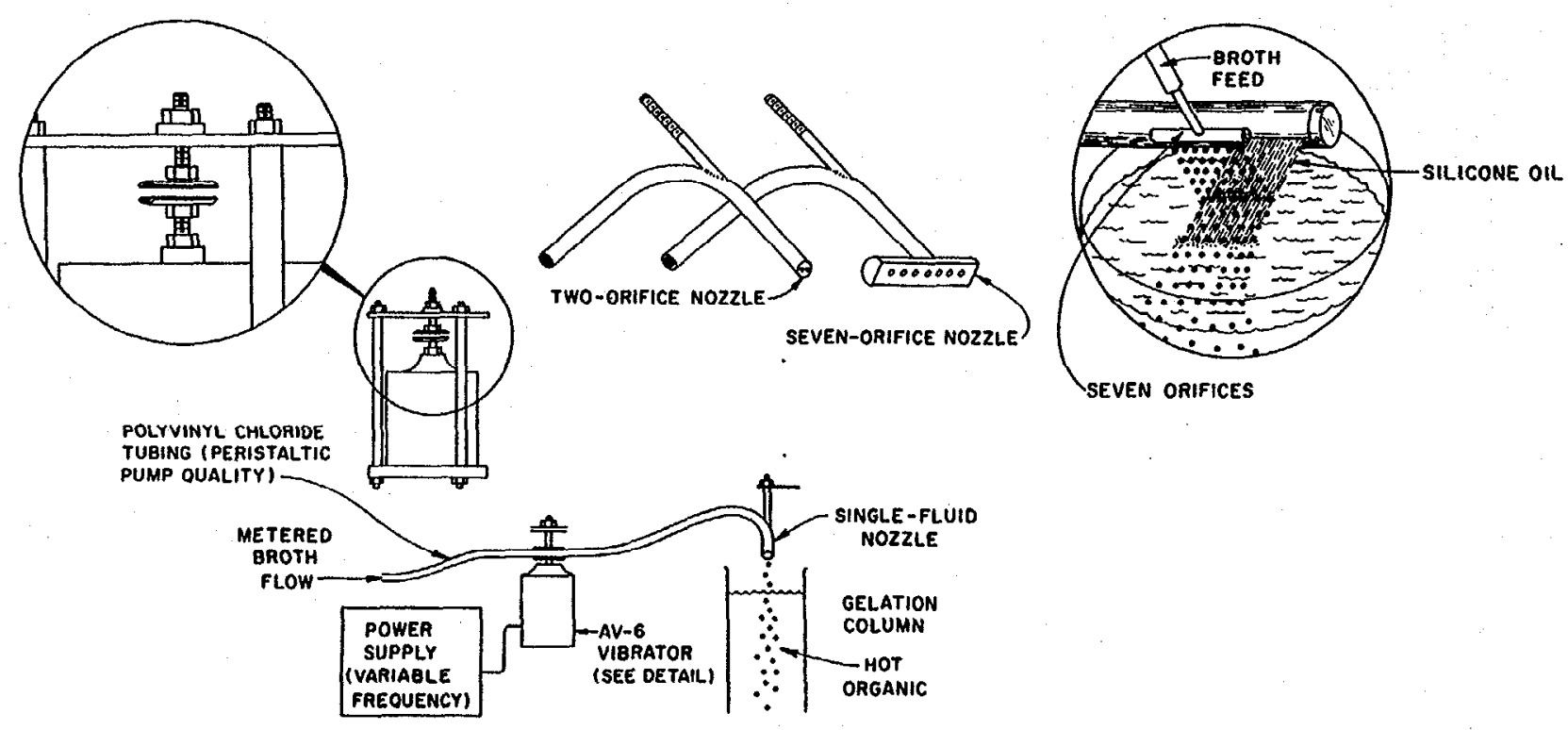

Fig. 4. Schematic of single-fluid pulsed tubular nozzles used to increase the production of microspheres. 
a chilled-broth pot, a two-fluid-nozzle system for controlling the size of the broth droplets, a glass gelation column (forming column), a downstream transport line to provide a residence time for the gel spheres to hydrolyze and solidify, and a product collector for holding and aging the gelled spheres as well as for separating the silicone oil from the gelled spheres.

The silicone oil reservoir was a stainless steel open-top rectangular container that was $7 \mathrm{in}$. wide by $8.25 \mathrm{in}$. long and $11.5 \mathrm{in}$. deep. Two 250 -W stainless steel heating blades were positioned at the rear of the reservoir to heat the oil. A thermocouple that was positioned in the basket at the bottom and near the front of the reservoir was connected to a Barber-Coleman Controller, which was used to regulate the oil temperature. A Thomas Magne-matic stirrer with a stainless steel shaft positioned between the two heating blades and a stainless steel impeller located near the bottom of the reservoir was used to mix and maintain the oil at the desired temperature. Most of the front space in the reservoir was used by a large, removable stainless steel wire-mesh $(150-\mu \mathrm{m})$ basket that served as a backup to prevent any spilled gelled spheres from being transferred from of the reservoir to the circulating pump.

An Eastern D-11 centrifugal pump was used to pump the hot oil from the reservoir through a 1/4-in.-ID stainless steel line to the vertically positioned glass gelation column. The flow from the pump was divided into two streams, each of which was controlled by manual valves. The flow of one of the streams was routed to a position that was about $9 \mathrm{in}$. above the center of the top of the gelation column. Vertically attached to this line was a 1/4-in.-ID, 3/8-in.-OD Nalgene tube whose outlet end was inserted about 2 in. into the entrance of the gelation column. The Nalgene tube was part of the two-fluid-nozzle system that was employed to control the size of the droplets. The other hot silicone oil stream from the pump was routed to the glass fitting at the bottom of the gelation column and flowed up through a shell surrounding the central gelation tube. The hot oil overflowed at the top of the column, first into the central tube and then into an overflow cup. A large Nalgene tube was connected to a glass fitting from the overflow cup to route the overflow back to the hot oil reservoir. During operation, the flow of oil from the heating shell was normally adjusted to provide only a slight overflow.

The two-fluid nozzle system was very simple; it consisted of a flat-tipped stainless steel hypodermic needle, 18 gauge (19 or 20 gauge could also be used), which was perpendicularly 
inserted through the wall of the Nalgene tube to the midpoint of the hot silicone oil carrier stream and was positioned approximately $5 \mathrm{in}$. above the entrance to the gelation column. The chilled broth was jetted into the laminar flowing oil by pressurizing (with air) the broth pot and forcing the broth out a tube at the bottom of the broth pot through a short Nalgene line that was connected to the hypodermic needle. The size of the droplets formed was dependent on the gauge of the needle used and the flow rates of both the hot silicone oil and the broth.

The hot oil carrying the droplets from the two-fluid nozzle tube flowed directly into the central concurrent flow tube of the jacketed gelation column, where it was desirable for the droplets to begin to gel. On exiting the gelation column, the gelling spheres flowed into a Nalgene serpentine transport line (1/4 in. ID and 1/16 in. OD). This line was long enough (about $8 \mathrm{ft}$ ) to allow the gelling spheres to have a total residence time of 25 to $35 \mathrm{~s}$ in the collection basket. The transport time also included the time the spherules were passing through the $62-\mathrm{cm}-1$ ong gelation column. The gelation column and the serpentine transport line were designed to be a siphoning system with a gravity head of about $60 \mathrm{~cm}$ for oil temperatures 65 to $95^{\circ} \mathrm{C}$.

The product collector, a cylindrical stainless steel wire-mesh $(150-\mu \mathrm{m})$ basket that was positioned above the hot oil reservoir, was used to collect and separate the gel spheres from the hot oil as it exited the serpentine transport line. The collected gel spheres were aged by lowering the product collector into the reservoir for $20 \mathrm{~min}$ (normally between 15 and $30 \mathrm{~min}$ ). After aging, the bulk of the oil was drained from the gel spheres and the residual oil was removed by a series of washing steps with trichloroethylene (TCE), then with $0.1 \mathrm{MNH}_{4} \mathrm{OH}$, and finally with deionized water to remove the reaction impurities.

Another basket of similar design was also positioned above the hot oil reservoir to filter the return oil from a Nalgene tube that was connected to the overflow drain line at the top of the gelation column.

Reaction temperature and gelation time are important variables in the process. The organic medium must be water immiscible and have a density slightly higher than that of the aqueous broth. Large droplets are formed most efficiently if there is a density difference of 0.05 to $0.10 \mathrm{~g} / \mathrm{cm}^{3}$ between the organic medium and the broth. (It can be less for small droplets.) Other important factors that need to be considered include flammability, toxicity, impurities, cost and disposal. The 
organic medium can be either a one-component solvent or a binary mixture. For example, TCE can be used at temperatures up to $65^{\circ} \mathrm{C}$. Silicone oils, such as Dow Corning Silicon Fluid 200, work well throughout the temperature range of 45 to $100^{\circ} \mathrm{C}$. Mixtures of $75 \%$ perchloroethylene (PERC) and $25 \%$ isoamyl alcohol (IAA) or $75 \%$ PERC and $25 \%$ hexanol can also be used at temperatures up to 90 and $85^{\circ} \mathrm{C}$, respectively. Microspheres that are formed and gelled in these mixtures or in TCE do not require an organic wash after the aging step. Organic forming media with high viscosities or boiling points (e.g., 2-ethyl-1-hexanol, silicone oil, or pure PERC), when drained from the microspheres after the aging step, leave a residual film on the microspheres that needs to be removed by washing with a more volatile organic. TCE, carbon tetrachloride, or hexane can be used for silicone oil; isopropyl alcohol for PERC; and carbon tetrachloride for 2-ethyl-1-hexanol. In a production facility, an organic medium that does not have to be removed from the microspheres by another organic agent would be more economical. Ideally the production of quality microspheres at the lowest cost would necessitate the use of a broth formulation that would allow the microspheres to be prepared at a low temperature in an organic medium that could be recycled and required no organic washes. For the present cost estimate, it was assumed that one of the PERC-alcohol mixtures would be employed as the gel-forming medium rather than silicone oil.

\section{ANNUAL COST ESTIMATE FOR LABORATORY-SCALE FACILITY}

For the basis of this economic evaluation, we chose a broth formulation for preparing HTiO microspheres that had a fairly rapid gelation time of 10 to17 $\mathrm{s}$ in the temperature range of 90 to $70^{\circ} \mathrm{C}$, respectively. Even at $60^{\circ} \mathrm{C}$, the gelation time was a usable $26 \mathrm{~s}$. The concentrations of the chemicals in the broth were as follows: $\mathrm{TiCl}_{4}(0.8 \mathrm{M})$, HMTA $(1.8 \mathrm{M})$, urea $(1.8 \mathrm{M})$, and $\mathrm{HCl}$ $(0.7 M)$. About $3.73 \mathrm{~L}$ of this broth would be needed to provide $1 \mathrm{lb}$ of air-dried HTiO microspheres that could be used as sorbent. The chemical composition of the microspheres is thought to be $\mathrm{Ti}\left(\mathrm{OH}_{4}\right) \bullet x \mathrm{H}_{2} \mathrm{O}$, where $x$ varies between 1 and 2 , depending on the drying time. In the drying process, it is best not to overdry the microspheres (remove the water of hydration).

Four terms are included in the total cost estimate: chemical (reagent) costs, manpower costs, and maintenance and capital charges. The chemical costs for preparing $1 \mathrm{lb}$ of HTiO microspheres 
are given in Table 1. The fact that the wet microspheres only have to be dried at ambient temperature should also help keep the production cost lower. The total cost of producing $1 \mathrm{lb}$ of spheroidal HTiO sorbent without recycling the wash solution is $\leq \$ 46.66$. It should be noted that this cost may be high for production operation because lower prices might be negotiated with a supplier for material of suitable quality. If the wash solution is recycled in order to reuse the HMTA and urea in broth preparations, the price of the chemicals would be $\leq \$ 37.53$. Recycling the wash solution would also help to minimize waste generation costs. In a study by R. J. Polley et al., ${ }^{15}$ it was found that the ideal conditions for the optimal preparation of HMTA was to mix ammonium salts with formaldehyde at a mol ratio of $2: 1.5$ and a pH of 6 to 8 in the temperature range of ambient to $40^{\circ} \mathrm{C}$. Concentration of the wash solution should be achieved by heating in an open tank at a temperature of less than $80^{\circ} \mathrm{C}$. Long-term heating of HMTA/urea solutions at $100^{\circ} \mathrm{C}$ can lead to the formation of other organics from the reaction of urea with HMTA. ${ }^{12}$ In addition to production economics, the recycle of formaldehyde is important for environmental reasons.

Table 1. Chemical costs for HTiO preparation

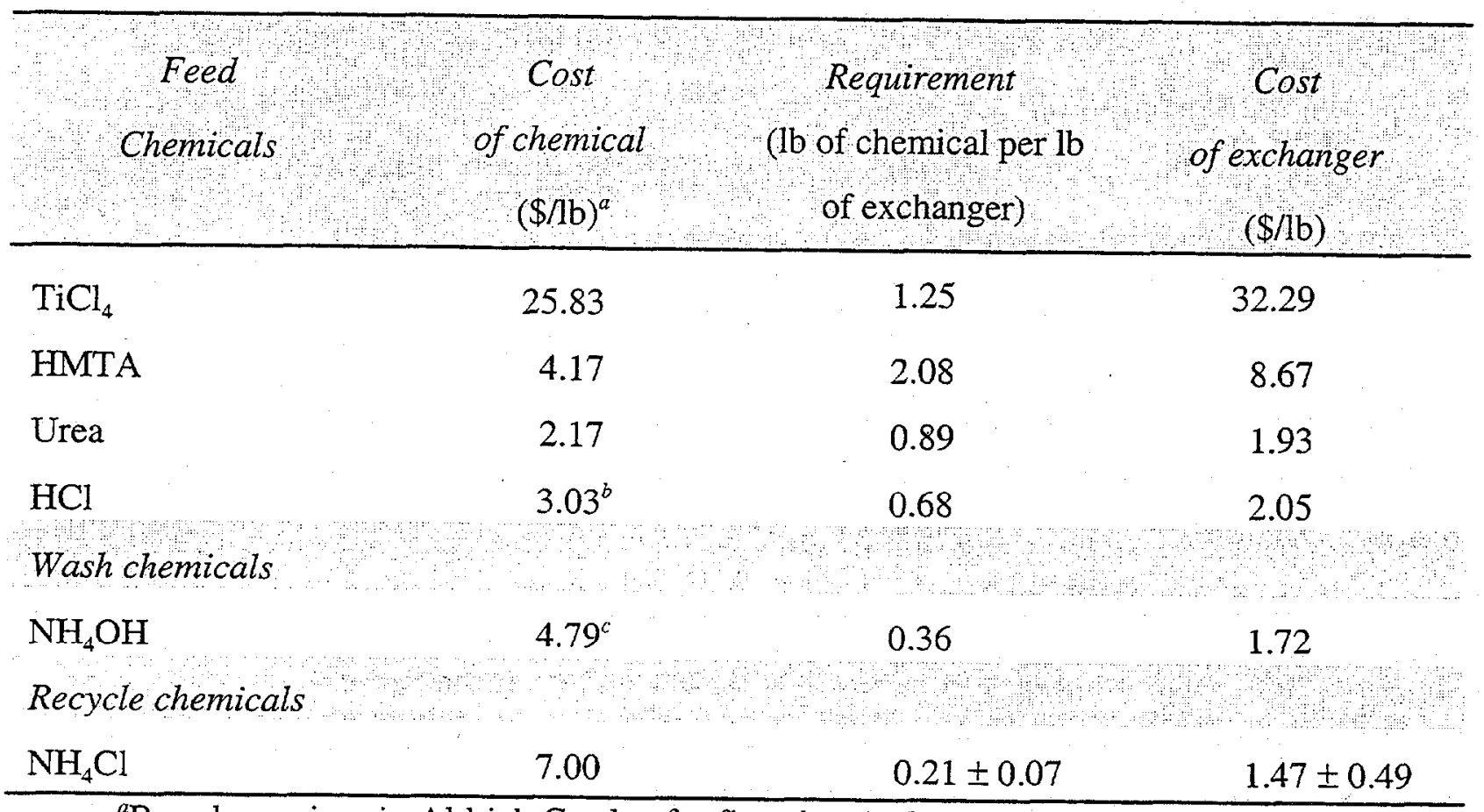

${ }^{a}$ Based on prices in Aldrich Catalog for fine chemicals.

${ }^{b} \$ 8.01 / \mathrm{L}(12.1 \mathrm{M})$.

$\$ 9.5 / \mathrm{L}(14.8 \mathrm{M})$. 
The manpower costs that are reported in Table 2 include fringe benefits and all other costs usually associated with operations. In the example shown here, "rent" of the facility is also included in the manpower costs. (Other companies may charge overhead to pay for operation of the building as a separate charge.) Manpower costs are also expected to be relatively insensitive to the scale of operation and would increase significantly only when additional shifts or more operators are required, such as for pilot-plant-scale operations.

Table 2. Manpower costs for system operation

\begin{tabular}{|c|c|c|c|c|}
\hline Employee & $34+4$ & $\begin{array}{c}\text { Time required } \\
\text { (h/year) }\end{array}$ & $\begin{array}{l}\text { Rate } \\
(\$ / h)\end{array}$ & $\begin{array}{l}\text { Cost } \\
(\$ \mathrm{~K} / \text { year })\end{array}$ \\
\hline Engineer & $\begin{array}{l}\text { Supervision, problem solving, } \\
\text { optimization }\end{array}$ & 208 & 70 & 14.6 \\
\hline $\begin{array}{l}\text { Technician } \\
\text { or chemical } \\
\text { operator }\end{array}$ & $\begin{array}{l}\text { Feed preparation, system } \\
\text { operation, chemical recycling, } \\
\text { and waste processing }\end{array}$ & 2080 & 50 & 104 \\
\hline Operating m & apower subtotal & & & -119 \\
\hline
\end{tabular}

The cost for the specific equipment needed for this operation is relatively small-estimated to be approximately $\$ 20 \mathrm{~K}$ for the bench-scale systems discussed here. The lifetime of a bench-scale operation should be relatively short, and a larger facility would probably be required after 2 to 4 years (after testing of the material has generated sufficient demand that a pilot-scale facility is needed). For this estimate, a charge of $\$ 10 \mathrm{~K} /$ year is estimated to cover depreciation and maintenance of the equipment. Because of the short lifetime of the equipment, the uncertainty in the maintenance costs, and the small contribution to the product cost, a more-detailed capital cost analysis or a present-worth analysis was not justified.

A summary of annual product costs during the early phases of production utilization is given in Table 3. Note that at this scale, the dominant term is manpower cost, which is approximately inversely proportional to the throughput and is likely to range between approximately $\$ 534$ and $\$ 286 / \mathrm{lb}$ for production scales of 260 to $520 \mathrm{lb} /$ year. With costs so dependent on manpower cost, it 
would be desirable to operate at a higher throughput for only part of the time; therefore, it is not unreasonable to expect costs of initial samples of the material to be in the range of $\$ 250$ to $\$ 400 / \mathrm{lb}$.

Table 3. Summary of annual product costs for laboratory-scale facility

\begin{tabular}{ll}
\hline Assume 1-lb/day production at 260 lb/year & Assume 2-lb/day production at 520 lb/year \\
\hline Chemical cost $=260 \mathrm{lb} /$ year $\times \$ 37.53=\$ 9,758$ & Chemical cost $=520 \mathrm{lb} /$ year $\times \$ 37.58=\$ 19,542$ \\
Manpower cost $=\$ 119,000$ (full burden) & Manpower cost $=\$ 119,000$ (full burden) \\
Equipment/maintenance/replacement $=\$ 10,000$ & Equipment/maintenance/replacement $=\$ 10,000$ \\
Total cost $=\$ 137,908$ & Total cost $=\$ 148,542$ \\
Cost $/ \mathrm{b}=\sim 534$ & Cost $/ \mathrm{lb}=\sim 286$ \\
\hline
\end{tabular}

\section{ANNUAL COST ESTIMATE FOR PILOT-SCALE FACILITY}

A pilot-scale facility with production-line equipment for preparing air-dried microspheres at the rate of 1 to $2.4 \mathrm{lb} / \mathrm{h}$ can also be built at modest costs. The production-line equipment would probably be based on modified designs that have been described in patents and reports by Haas et al., ${ }^{11}$ Williams, ${ }^{9}$ and Kilian et al. ${ }^{16}$ Many of the components of these systems are similar because they are based on the engineering design concepts described by Williams ${ }^{9}$ (Figs. 5 and 6). Exxon's system $^{18}$ was of similar design, but the Exxon engineers modified several components to make them more efficient and productive. The gel-forming system used by Haas et al. ${ }^{11}$ (Figs. 7 and 8) seemed to simplify the process even more. Procedures and equipment were developed using PERC as the organic gelation medium. A trough (Fig. 8), which was improved after initial testing, was designed to replace the gelation-forming column. Production rates of $2.4 \mathrm{lb} / \mathrm{h}$ were achieved, and equipment performance and product uniformity were successfully demonstrated. A modified system of this type might be an important "next step" for Eichrom or any other company that might want to use this technology to prepare sorbents or catalysts. A simpler drying system might need to be designed in which the washed microspheres would be conveyed to large drying trays that would automatically be inserted and stacked in open-ended racks with about 1-in. gaps between the trays to allow heated 


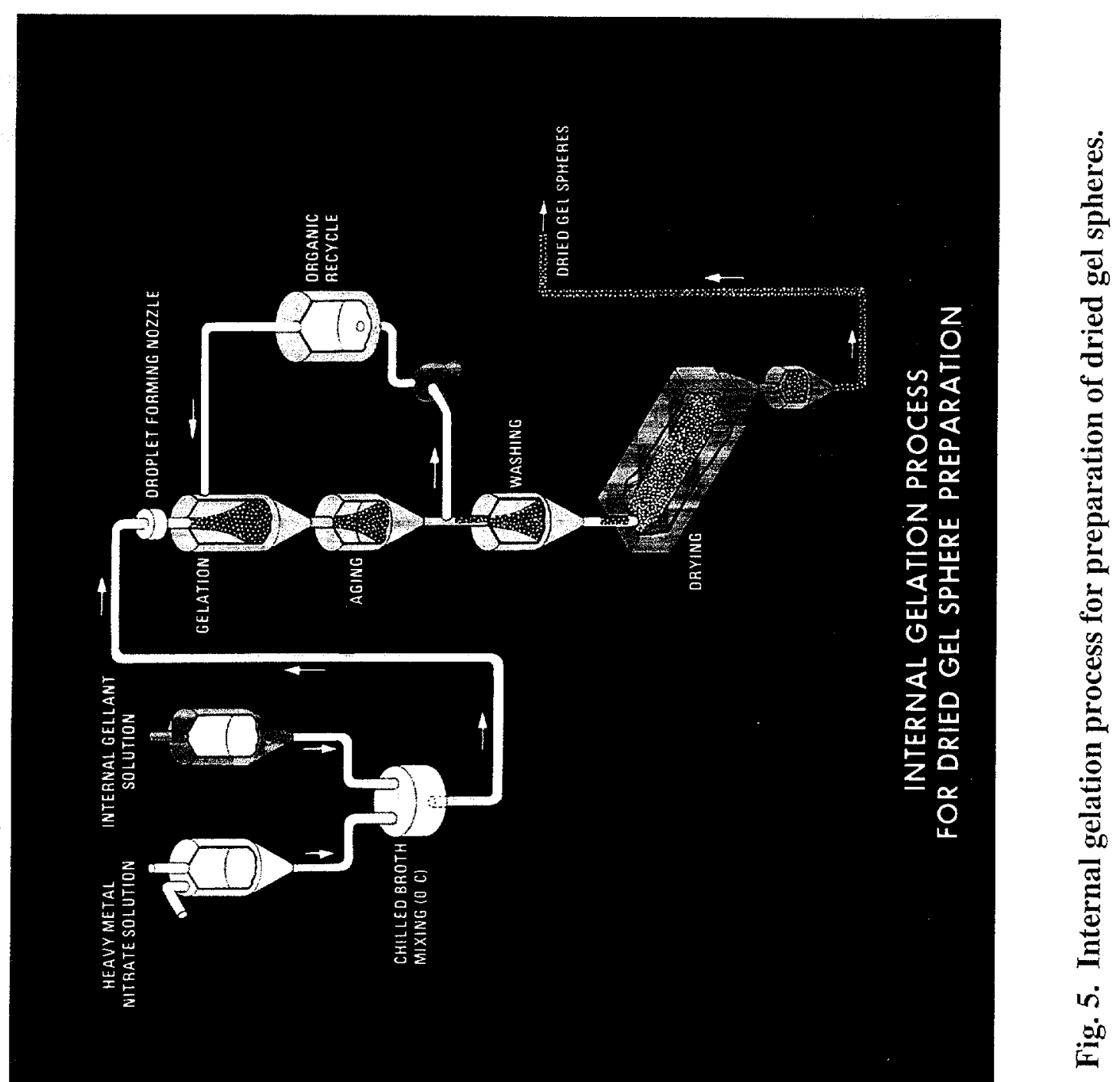




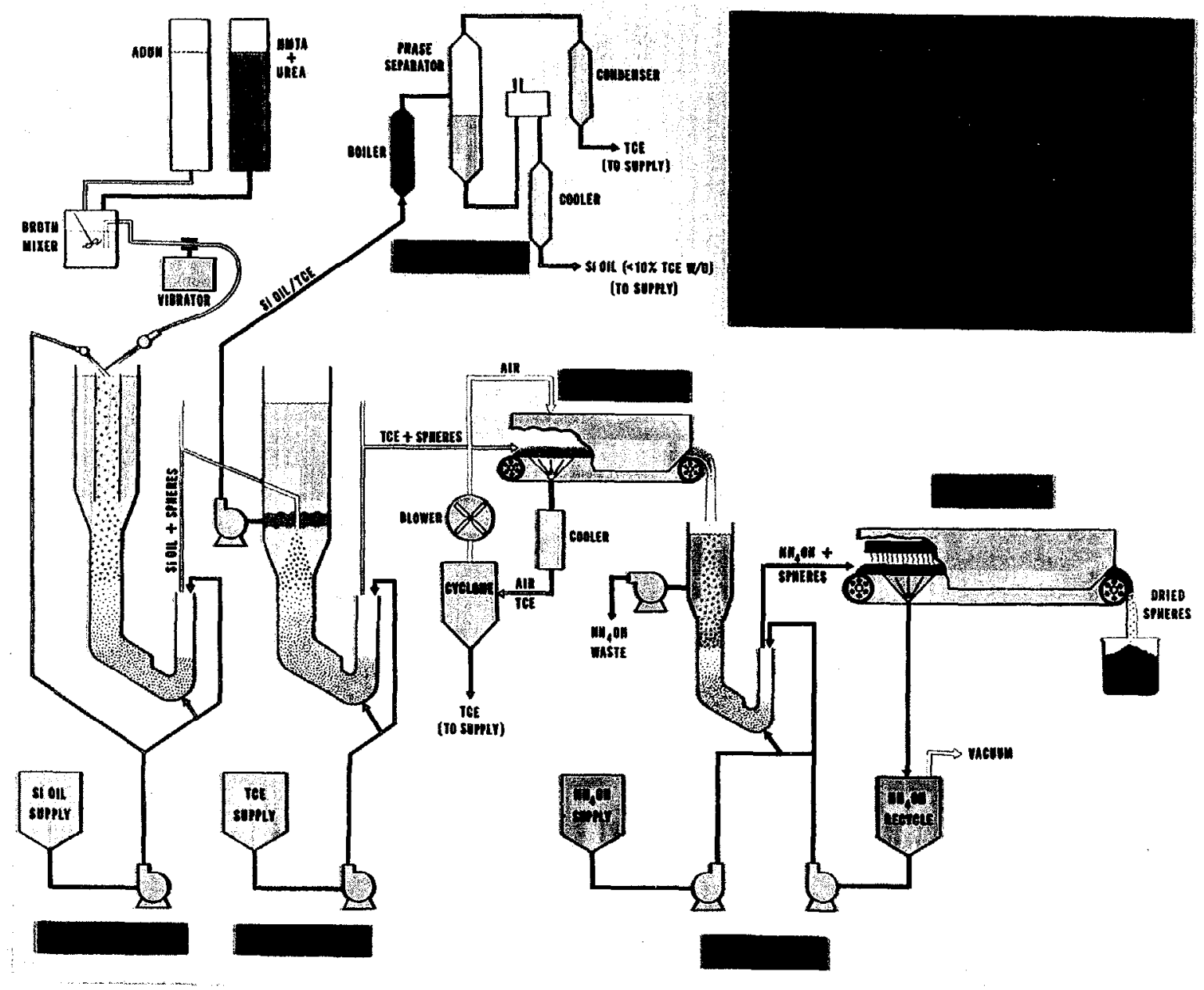

Fig. 6. Continuous internal gelation concepts using silicone oil and trichloroethylene wash. 

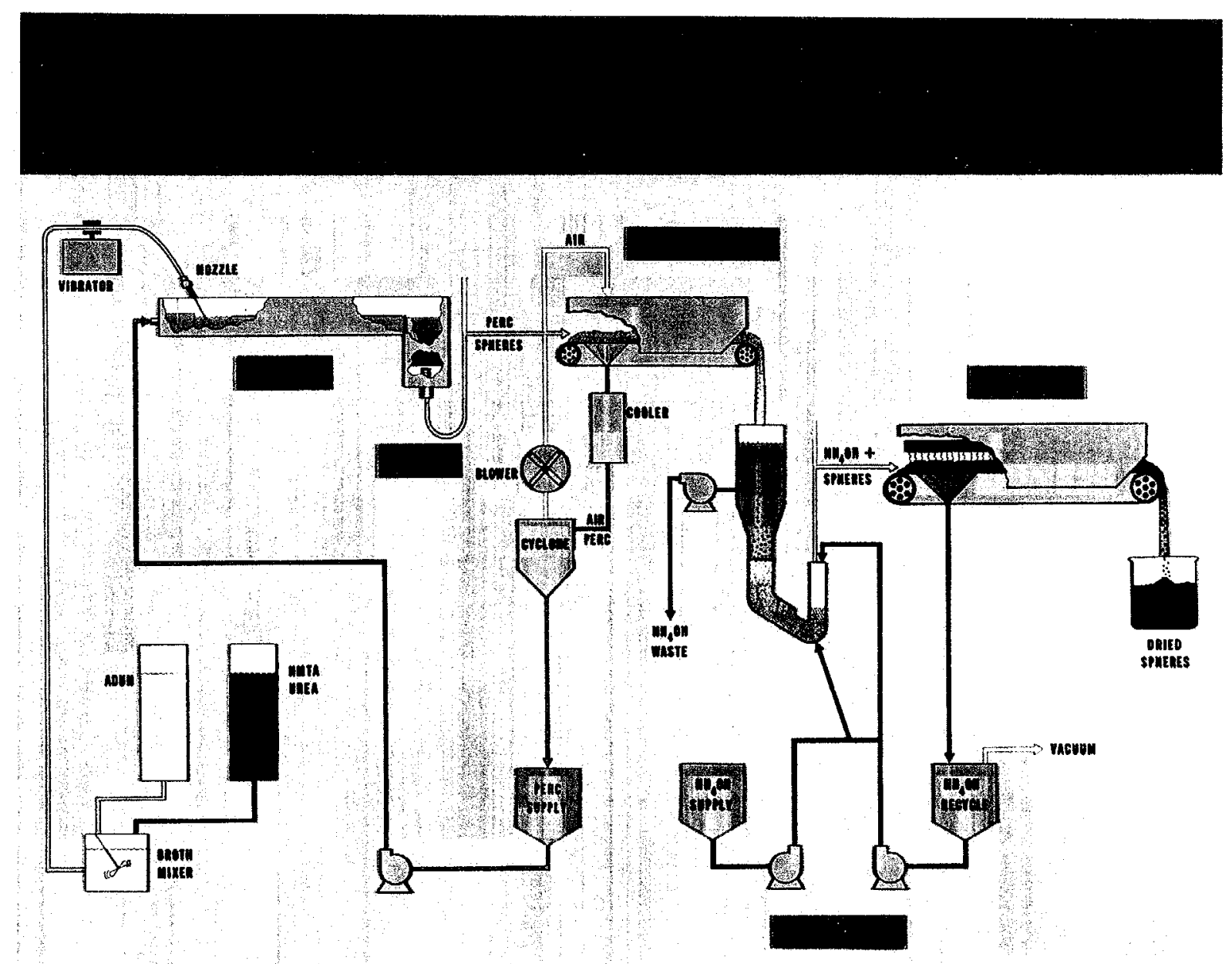

Fig. 7. Schematic of continuous perchloroethylene-based gel sphere engineering facility. 


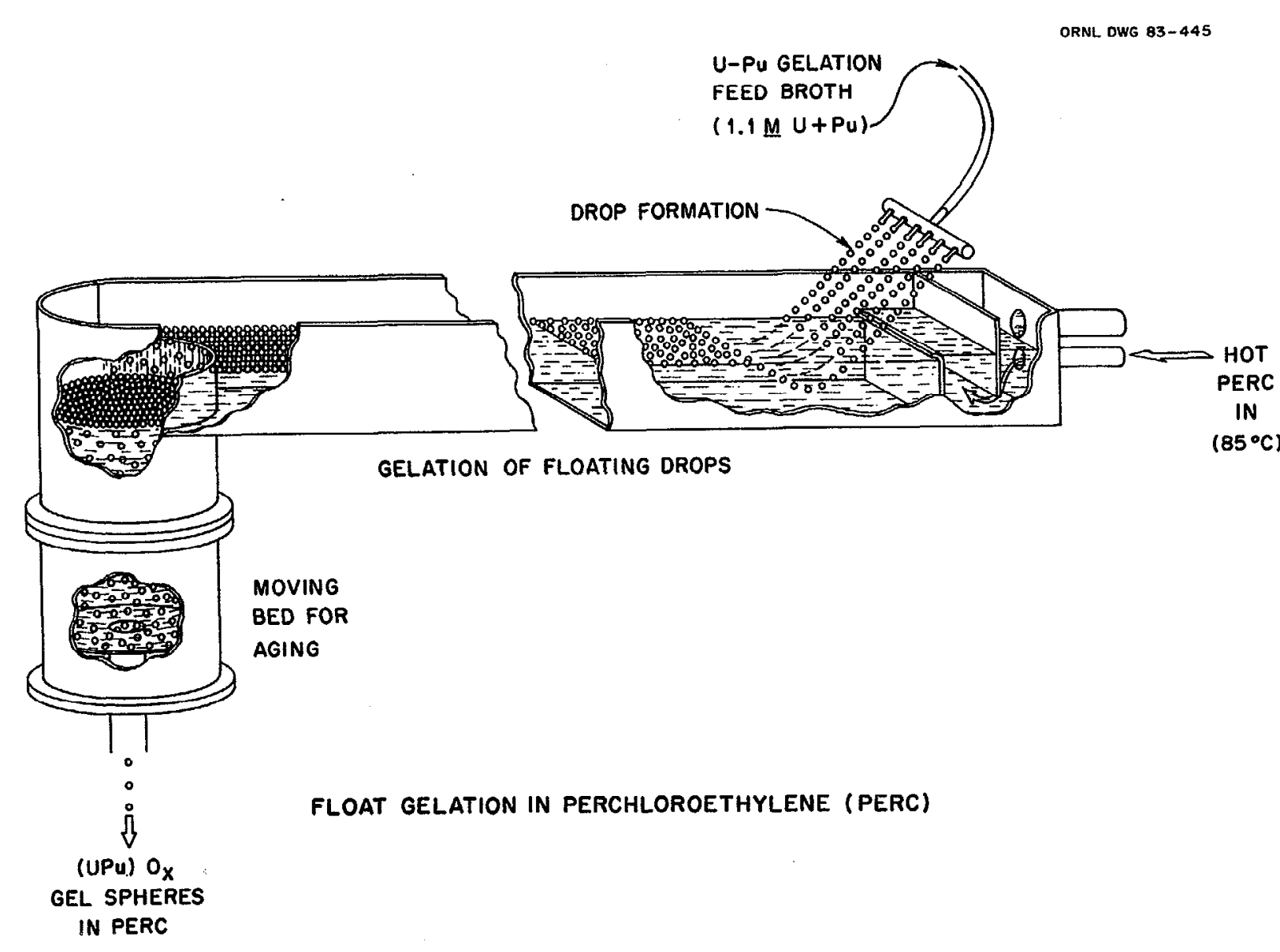

Fig. 8. Initial design of float-gelation trough for using perchloroethylene as the water-immiscible organic medium. 
air to pass over the microspheres. Each tray could be covered with two to three layers of microspheres. The racks would be moved into a drying room, which would have a constant flow of moist heated air. The temperature of the microspheres should be kept below $50^{\circ} \mathrm{C}$ to maintain the water of hydration. Drying equipment such as that described by Williams, ${ }^{9} \mathrm{Haas}$ et al., ${ }^{11}$ and Kilian et al. ${ }^{16}$ could be employed to make catalyst in which the HTiO would be converted to titanium oxide.

The most important factor in making composite microspheres to be used as sorbents is the design of the broth mixing vessel. A predetermined mass of fine powder of the sorbent or catalyst would be added to the mixed broth and kept in suspension with a mixing system. A baffle at the opening to the broth supply line to the microsphere-forming device would keep the line from plugging. Normally, this line is kept as short as possible and can be vibrated. Adding $0.5 \mathrm{lb}$ of powder to a volume of broth formulation equivalent to $1 \mathrm{lb}$ of air-dried HTiO microspheres would provide a total mass of composite microspheres of $1.5 \mathrm{lb}$. The preparation or purchase costs of an additive would increase the cost per pound of composite microspheres. The cost of the composite microspheres on a mass basis is the weighted average of the cost of the additive and the HTiO microspheres. Thus, the per-pound cost of the composite microspheres would be less than that of the pure HTiO microspheres if the per-pound cost of the additive were lower than the per-pound cost of the pure HTiO microspheres.

As stated earlier, the four terms that need to be included in the total cost estimate are the chemical (reagent) costs, manpower costs, and maintenance and capital charges. In estimating the cost of producing air-dried microspheres at the rate of $2.4 \mathrm{lb} / \mathrm{h}$, the cost of chemicals to prepare a pound of sorbent would remain the same as that for the laboratory-scale facility, about $\$ 37.53$ (see Table 1). This value assumes that the wash solutions are recycled in order to reuse the HMTA and urea. If a pilot-scale facility were to operate on a 24 -h schedule, 5 days per week, it would require two operators for each 8-h shift. In the case of a multiple-operation plant, one full-time technician with the half-time assistance of another technician might be enough labor. For this estimate, we will assume that two technicians will be needed. Table 4 gives the estimate for the fully burdened manpower costs. 
The price of production equipment, including controls, is estimated to be in the range of $\$ 200 \mathrm{~K}$ to $\$ 500 \mathrm{~K}$. The equipment costs would have only a small impact on the cost per pound if the equipment could be used for a number of years. It will be assumed that the cost of the production equipment and controls cost is the larger value $(\$ 500 \mathrm{~K})$ and production lasts 5 years. If there is a long-term demand for production, the equipment, which is durable, could last much longer. The higher estimated average cost for the 5-year period would be between $\$ 100 \mathrm{~K}$ and $\$ 130 \mathrm{~K} / \mathrm{year}$, which also includes depreciation, interest, and maintenance. The larger estimated value of $\$ 130 \mathrm{~K} / \mathrm{year}$ was chosen to ensure that replacement equipment and repairs were included.

Table 4. Manpower costs for system operation

\begin{tabular}{llccc}
\hline Employee & \multicolumn{1}{c}{ Task } & $\begin{array}{c}\text { Time required } \\
\text { (h/year) }\end{array}$ & $\begin{array}{c}\text { Rate } \\
(\$ / \mathrm{h})\end{array}$ & $\begin{array}{c}\text { Cost } \\
\text { (\$K/year) }\end{array}$ \\
\hline Engineer & $\begin{array}{l}\text { Supervision, problem solving, } \\
\text { optimization }\end{array}$ & 416 & 70 & $\sim 29$ \\
Technician & $\begin{array}{l}\text { Feed preparation, system } \\
\text { operation, chemical recycling } \\
\text { and waste processing }\end{array}$ & 12,480 & 50 & $\sim 624$ \\
\hline Operating manpower subtotal
\end{tabular}

Table 5 gives the estimated costs for a pilot-scale facility that can produce 5.6 tons of airdried microspheres per year for use as sorbent or catalyst. At this rate, the cost per pound of sorbent would be about $\$ 107$. For a larger facility, in which a technician's time could be shared, the same work might be done with 1.5 -person shifts. If this were the case, the price per pound of sorbent might be decreased by $15 \%$ to about $\$ 93$.

The cost of making microspheres will be strongly dependent on the scale of the pilot facility and the fraction of the time it is used. Some companies may have existing facilities that would be suitable for producing the material in campaigns with little or no modification. That is, it may be possible to prepare this material between the campaigns conducted to make other products. In such cases, the cost of the pilot-scale quantities of microspheres would be relatively low. There is 
obviously no practical way to determine accurately the cost of making the material in the facilities of different companies, but knowing that the chemical cost alone is likely to be approximately $\$ 40 / 1 \mathrm{~b}$ and that the product can be prepared in a bench-scale facility for as little as $\$ 300 / \mathrm{lb}$, one can estimate that a pilot facility might be able to prepare the material at a total cost of $\$ 90$ to $\$ 150 / \mathrm{lb}$ at production rates of a few tons/year.

Table 5. Summary of annual product costs for a pilot-scale facility at $2.4-\mathrm{lb} / \mathrm{h}$ production

Assume $43.2-1 \mathrm{~b} /$ day production at $11,232 \mathrm{lb} /$ year $^{a}$

Chemical cost per year $=11,232 \mathrm{lb} /$ year $\times \sim 37.53=\sim \$ 421,500$

Manpower cost $=\sim \$ 653,000$ (full burden)

Capital, maintenance, depreciation $=-\$ 130,000$

Total cost $=\sim \$ 1,205,000$

Cost per pound $=-\$ 107$

${ }^{a}$ Pounds sorbent produced per year $=(2.4 \mathrm{lb} / \mathrm{h})(18$-h production/day $)(5$ days $/$ week $)(52$ weeks/year $)$ $=11,232 \mathrm{lb} /$ year.

If the manpower, capital, and maintenance costs scale as the throughput to the 0.5 power and the chemical costs remain constant, the cost for 2 tons/year would be approximately $\$ 120 / 1 \mathrm{~b}-\mathrm{a}$ value that lies within the estimated range. This could even be a conservative estimate since manpower costs at this scale of operation might vary with a smaller power of the throughput and the cost of chemicals could be much less than that used in the estimates. Such scaling powers are usually most successful when the labor and capital costs are likely to be proportional. Note also that scaling the costs in this manner even for equipment is less reliable when the nature of the equipment changes, as is likely to happen in the transition from bench-scale to pilot-scale facilities; however, this may not represent a serious uncertainty in the final costs until the capital costs become a dominant term. 


\section{ACKNOWLEDGMENTS}

This research was sponsored by the Efficient Separations and Processing Crosscutting Program, Office of Science and Technology, U.S. Department of Energy. The authors wish to thank the reviewers Nick Korte and Roger Spence, of the Chemical Technology Division for their technical review of the manuscript, and Brenda Johnson, of the Chemical Technology Division, for preparation of the final report.

\section{REFERENCES}

1. A. K. De and A. K. Sen, "Synthetic Inorganic Ion-Exchangers," Sep. Sci. Technol. 13(6), $517-40(1978)$.

2. A. Clearfield, Ed., Inorganic Ion Exchange Materials, CRC Press, Boca Raton, Fla.,1982.

3. E. W. Hooper, B. A. Phillips, S. P. Dagnall, and N. P. Monckton, An Assessment of the Application of Inorganic Ion Exchangers to the Treatment of Intermediate Level Wastes, AERE-R-11088, Atomic Energy Research Establishment, Harwell, 1984.

4. J. L. Collins, D. J. Davidson, C. W. Chase, B. Z. Egan, D. D. Ensor, R. M. Bright, and D. C. Glasgow, Development and Testing of Ion Exchangers for Treatment of Liquid Wastes at Oak Ridge National Laboratory, ORNL/TM-12315, Oak Ridge National Laboratory, March 1993.

5. J. L. Collins, B. Z. Egan, K. K. Anderson, C. W. Chase, J. E. Mrochek, J. T. Bell, and G. E. Jernigan, Evaluation of Selected Ion Exchangers for the Removal of Cesium from MVST W-25 Supernate, ORNL/TM-12938, Oak Ridge National Laboratory, April 1995.

6. J. L. Collins, "Method of Preparing Hydrous Titanium Oxide Spherules and Other GelForms Thereof," U.S. Patent 5,821,186, Oct. 13, 1998.

7. J. L. Collins, M. H. Lloyd, and R. L. Fellows, "The Basic Chemistry Involved in the Internal-Gelation Method of Precipitation of Uranium as Determined by pHMeasurements," Radiochim. Acta 42, 121-34 (1987). 
8. P. A. Haas, J. M. Begovich, A. D. Ryon, and J. S. Vavruska, "Chemical Flowsheet Conditions for Preparing Urania Spheres by Internal Gelation," Ind. Eng. Chem. Prod. Res. Develop. 19( 3), 459-67 (September 1980).

9. D. F. Williams, Oak Ridge National Laboratory, personal communication, October 1980.

10. M. H. Lloyd, "Coprocessed Nuclear Fuels Containing (U, Pu) Values as Oxides, Carbides, or Carbonitrides," U.S. Patent 4,397,778, Aug. 9, 1983.

11. P. A. Haas, V. L. Fowler, and M. H. Lloyd, "Preparation of Nuclear Fuel Spheres by Flotation-Internal Gelation," U.S. Patent 4,663,093, May 5, 1987.

12. J. L. Collins, M. H. Lloyd, and S. E. Shell, "Method of Controlling Crystallite Size in Nuclear-Reactor Fuels," U.S. Patent 4,502,987, Mar. 5, 1985.

13. A. H. Bond, M. J. Gula, J. T. Harvey, J. M. Duffey, E. P. Horwitz, R. D. Rogers, and J. L. Collins, "Flowsheet Feasibility Studies Using ABEC ${ }^{\oplus}$ Resins for Removal of Pertechnetate from Nuclear Wastes," Ind. Eng. Chem. Res., in press, 1999.

14. P. A. Haas, "Formation of Uniform Liquid Drops by Application of Vibration to Laminar Jets," Ind. Eng. Chem. Res. 31( 3), 959-67 (1992).

15. J. R. Polley, C. A. Winkler, and R. V. V. Nicholls, "Studies of the Formation of Hexamine from Formaldehyde and Ammonium Salts in Aqueous Solution," Can. J. Res. 25, Sect. B., 525-34 (1947).

16. D. C. Kilian, S. S. Koegler, and L. D. Gerrald, Sphere-Pac Fuel Development Program SemiAnnual Progress Report, DOE/ET/34026-5, Exxon Nuclear Company, Inc., June 1982.

17 S. S. Koegler, Development of Multiple-Sphere Forming Apparatus for a Sphere-Pac Fuel Production Facility, XN-RT-41, Exxon Nuclear Company, Inc., December 1981.

18. L. D. Gerrald, Development of a Prototype, Continuous Dryer for Sphere-Pac Fuel, XN-RT-30, Exxon Nuclear Company, Inc., March 1982. 
ORNL/TM-1999/212

\title{
INTERNAL DISTRIBUTION
}

\author{
1. K. K. Anderson \\ 2. C. W. Chase \\ 3-12. J. L. Collins \\ 13. R. T. Jubin \\ 14. L. N. Klatt \\ 15. L. E. McNeese \\ 16. R. D. Spence \\ 17. J.S. Watson \\ 18. ORNL Laboratory Records--RC \\ 19. Central Research Library \\ 20-21. ORNL Laboratory Records-OSTI
}

\section{EXTERNAL DISTRIBUTION}

22. J. J. Duteau, Science Applications International Corporation, EM-53, 555 Quince Orchard Road, Suite 500, Gaithersburg, Maryland 20878

23. J. L. Harness, Department of Energy, Oak Ridge Operations, Office of Science and Technology, P.O. Box 2001, Oak Ridge, Tennessee 37831-8620

24. D. Lillian, Department of Energy, Office of Science and Technology, EM-53 CL, 19901 Germantown Road, Germantown, Maryland 20874

25. J. McGlynn, Science Applications International Corporation, EM-53, 555 Quince Orchard Road, Suite 500, Gaithersburg, Maryland 20878

26. I. Tasker, Unitec, 9 East Second Street, Suite 1, Frederick, Maryland 21701

27. M. C. Thompson, Westinghouse Savannah River Company, Savannah River Technology Center, Building 773-A, Aiken, South Carolina 29808 


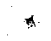

$x$ 